\title{
Innate immunity and effector and regulatory mechanisms involved in allergic contact dermatitis*
}

\author{
Marilene Chaves Silvestre ${ }^{1}$ \\ Vitor Manoel Silva dos Reis ${ }^{3}$
}

\author{
Maria Notomi Sato ${ }^{2}$
}

DOI: http:/ / dx.doi.org/10.1590/abd1806-4841.20186340

\begin{abstract}
Skin's innate immunity is the initial activator of immune response mechanisms, influencing the development of adaptive immunity. Some contact allergens are detected by Toll-like receptors (TLRs) and inflammasome NLR3. Keratinocytes participate in innate immunity and, in addition to functioning as an anatomical barrier, secrete cytokines, such as TNF, IL-1 $\beta$, and IL-18, contributing to the development of Allergic Contact Dermatitis. Dendritic cells recognize and process antigenic peptides into T cells. Neutrophils cause pro-inflammatory reactions, mast cells induce migration/maturation of skin DCs, the natural killer cells have natural cytotoxic capacity, the $\gamma \delta$ T cells favor contact with hapten during the sensitization phase, and the innate lymphoid cells act in the early stages by secreting cytokines, as well as act in inflammation and tissue homeostasis. The antigen-specific inflammation is mediated by T cells, and each subtype of T cells (Th1/Tc1, Th2/Tc2, and Th17/Tc17) activates resident skin cells, thus contributing to inflammation. Skin's regulatory T cells have a strong ability to inhibit the proliferation of hapten-specific T cells, acting at the end of the Allergic Contact Dermatitis response and in the control of systemic immune responses. In this review, we report how cutaneous innate immunity is the first line of defense and focus its role in the activation of the adaptive immune response, with effector response induction and its regulation.
\end{abstract}

Keywords: Allergy and immunology; Dermatitis, allergic contact; Dermatitis, contact

\section{INTRODUCTION}

Allergic Contact Dermatitis (ACD) is a generally eczematous, inflammatory skin disease, which begins at the location of contact with the allergen, after sensitization occurs, which is constituted by successive exposure to the allergen, provoking the activation of the immune system. ${ }^{1,2}$ The occurrence of cutaneous manifestations clinically represents the elicitation stage, followed by the immune resolution stage. ${ }^{2}$

Currently, it is known that, in ACD, the immune mechanisms involve both innate and adaptive immunity, and that, in the sensitization stage, the mere presence of the antigen is insufficient to generate an immune response, which requires the activation of the innate immune system. ${ }^{3}$

The contact allergens are low-weight molecules (less than 500 doltons), which needs to be linked, by covalent bonds, to a protein in the epidermis to generate a new antigenic determinant. ${ }^{3,4}$ By contrast, the sensitization to the metallic ions (nickel, chrome, cobalt, etc.) generate non-covalent bonds, which are capable of stimulating the immune response. ${ }^{4}$ The hapten induces sensitization due to its pro-inflammatory properties, with the capacity to activate the innate immunity of the skin and emit signals that induce the recruitment, migration, and maturation of Dendritic Cells (DCs). ${ }^{4}$

Two phases occur for the development of ACD: sensitization and elicitation. ${ }^{3}$

Sensitization stage (afferent stage or induction stage): this occurs after weeks or months of repeated exposure of the sensitizing agent to the skin. ${ }^{3}$ The compounds formed between the hapten and a protein are processed by the skin's DCs, migrate to the Draining Lymph Nodes (dLNs), from which, in their paracortical regions, the antigen-specific T CD8+ and CD4+ lymphocytes originate, differentiating them from Th1 and Th17 effector cells and Cytotoxic T Lymphocytes (CTLs). This phase occurs between 10 and 15 days.-5

\footnotetext{
Received on 03.08.2016.

Approved by the Advisory Board and accepted for publication on 09.01.2017.

* Work performed at the Faculdade de Medicina, Universidade de São Paulo (FMUSP), São Paulo (SP), Brazil.

Financial support: None.

Conflict of interest: None.

Department of Tropical Medicine and Dematology, Dematology Service, Universidade Federal de Goiás (UFG), Goiânia (GO), Brazil.

2 Department of Dermatology, Medical Investigation Laboratory (LIM 56), Instituto de Medicina Tropical, Faculdade de Medicina da Universidade de São Paulo (FMUSP), São Paulo (SP), Brazil.

3 Department of Dermatology, Faculdade de Medicina da Universidade de São Paulo (FMUSP), São Paulo (SP), Brazil.
}

MAILING ADDRESS:

Marilene Chaves Silvestre

Email: marilene.silvestre@terra.com.br 
Elicitation stage (efferent stage or effector stage): In this stage, the reexposure to the same hapten leads to the appearance of $A C D$ through the recruitment of the Th1 and Th17 cells and CTLs to the skin, in which the CTLs induce the apoptosis of the keratinocytes. At the same time, there is the generation of the regulator T CD4+ cells (Tregs), capable of inhibiting ACD, mediating the tolerance in unallergic individuals..$^{3-5}$ This stage can last from 24 to 72 hours, presenting clinical signs of inflammation. ${ }^{6,7}$ These appear as a cutaneous eruptive process, which can fall under many clinical modalities: erythematous-vesicular lesions or erythematous-vesicular-secreting lesions or erythematous-secreting-infiltrative-lichenified lesions, with pruritus representing a constant symptom of variable intensity. ${ }^{8}$

Resolution stage: evidence has shown that the Tregs control the expansion of $\mathrm{T} \mathrm{CD} 8+$ cells in the lymph node and its activation in the skin. ${ }^{3}$

In this review, we report how the contact allergens promote inflammation through the activation of innate immunity, its cooperation amongst them, and with $\mathrm{T}$ cells to begin and guide early responses to contact allergens and the actions of Treg cells in the control of cutaneous inflammation (Chart 1).

\section{INNATE IMMUNITY}

Cutaneous innate immunity constitutes the first line of defense as well as plays a key role in the activation of the adaptive immune response, which represents the second line of defense. ${ }^{9}$

Innate immunity is characterized by its ability to recognize pathogens, such as viruses, bacteria, and fungi, that is, Pathogen-As-

\begin{tabular}{|ll|}
\multicolumn{1}{|c}{ ChART 1: Main abbreviations } \\
- & Dendritic Cells (DCs) \\
- & Dermal Dendritic Cells (dDCs) \\
- & Langerhans Cells (LCs) \\
- & Draining Lymph Nodes (dLNs) \\
- & Cytotoxic T Lymphocytes (CTLs) \\
- & Regulator T CD4+ cells (Tregs) \\
- & Pathogen-Associated Molecular Patterns (PAMPs) \\
- & Pattern Recognition Receptors (PRRs) \\
- & Damage-Associated Molecular Patterns (DAMPs) \\
- & Toll-like Receptors (TLRs) \\
- & Antigen-Presenting Cells (APCs) \\
- & Hyaluronic Acid (HA) \\
- & Nickel (Ni2+) \\
- & NLR3 NOD-Like Receptor (NLR) \\
- & Adenosine Triphosphate (ATP) \\
- & Natural Killer (NK) Cells \\
- & T-Cell Receptors (TCRs) \\
- & Innate Lymphoid Cells (ILCs) \\
- & Thymic Stromal Lymphopoetin (TSLP) \\
- & Granulocyte-Macrophage Colony-Stimulating Factor \\
\hline & (GM-CSF) \\
\hline
\end{tabular}

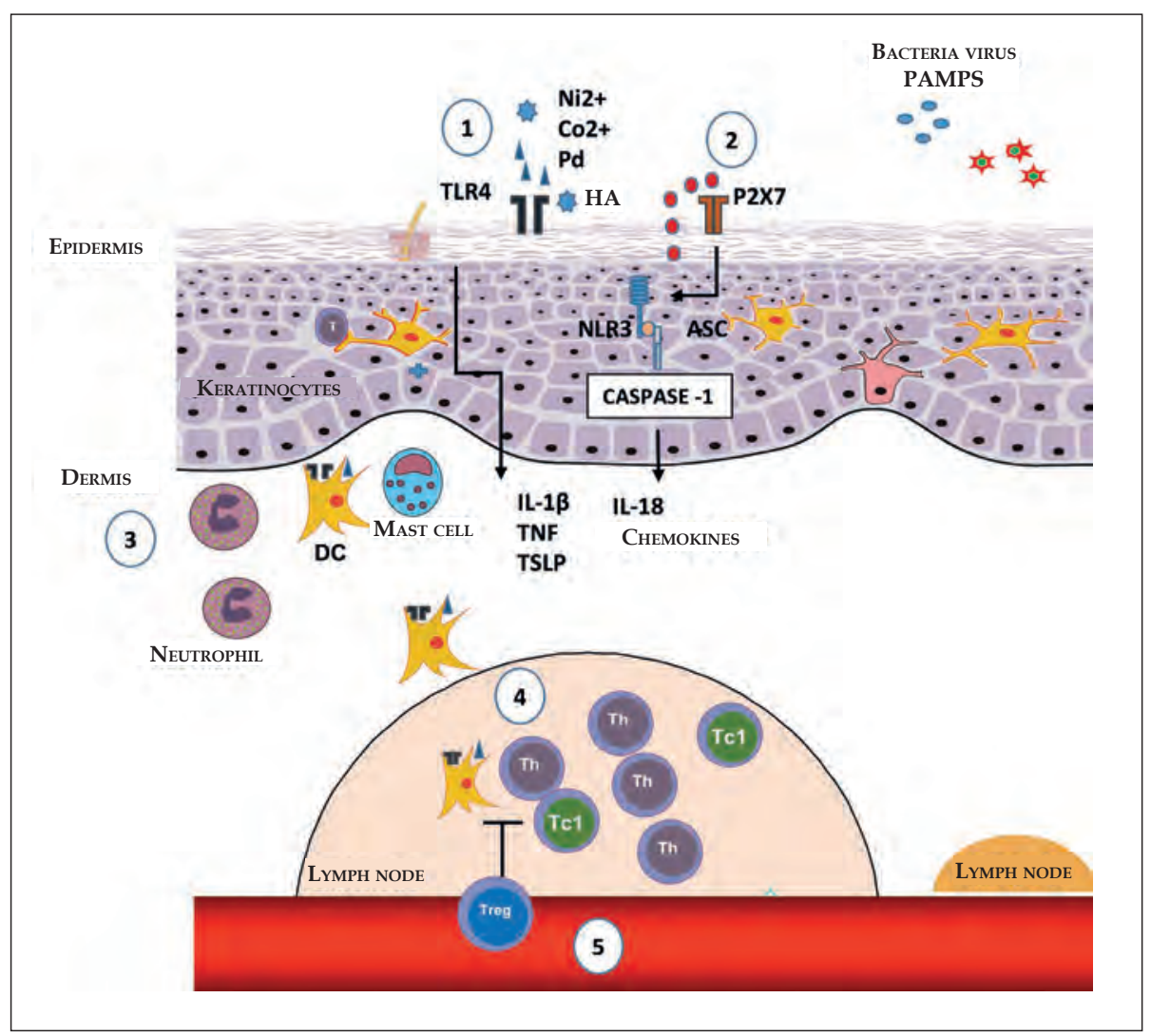

Figure 1: Initial stages of the sensitization in contact dermatites. 1) The nickel $(\mathrm{Ni2}+)$, cobalt $(\mathrm{Co} 2+)$ and palladium $(\mathrm{Pd})$ ions, or fragments of hyaluronic acid (HA) generated by some contact allergens, can directly trigger TLR4 and the NFKB pathway, culminating in the production of pro-inflammatory cytokines and chemokines. 2) The extracellular ATP acts as a danger signal (DAMP); upon binding with the P2X7 perigenetic receptor, it triggers the inflammasome through NLR3 and caspase-1, promoting the maturation of IL-1 $\beta$ and IL-18. 3) The production of cytokines and chemokines, by the keratinocytes, and the activation through TLR4 in DCs favors their maturation and migration, which is optimized with the presence of neutrophils and mast cells. 4) In $\mathrm{dLNs}$, the DCs present the antigen for the induction of antigen-specific T effector cells, which can generate Th or T CD8+ cells which secrete IFN- $\gamma$ (Tc1). 5) The regulation of Tregs in the sensitization stage, acting in the antigenic presentation and/or in the generation of effector $\mathrm{T}$ cells 
sociated Molecular Patterns (PAMPs), through a limited number of receptors, called Pattern Recognition Receptors (PRRs). ${ }^{10,11}$ These are expressed by various cell types, including macrophages, monocytes, DCs, neutrophils, keratinocytes, and epithelial cells, and allow for an early detection of pathogens in the location of infection (Figure 1). ${ }^{11}$

The PRRs are able to recognize the Damage-Associated Molecular Patterns (DAMPs), which are molecules that can be released during cell death. ${ }^{3}$ DAMPs include a group of many proteins, nucleic acids, and glycosaminoglycans. DAMPs and PRRs play a key role in ACD., ${ }^{1,12}$

\section{Toll-like Receptors (TLRs)}

TLRs are a family of receptors that recognize a wide variety of bonds, including lipids, lipoproteins, proteins, and nucleic acids. ${ }^{3}$ These receptors are expressive, especially in Antigen-Presenting Cells (APCs), epithelial, endothelial, and keratinocyte cells, working as a bond between innate and specific immunity. ${ }^{13,14}$ Have been identified 10 TLRs in humans and 12 in mice. ${ }^{15}$ The TLRs are expressed extracellularly as TLR $1,2,4,5,6$, and 11 , which mainly recognize lipids, lipoproteins, and proteins. ${ }^{16}$ By contrast, other TLRs are expressed intracellularly, in the endoplasmic reticulum, endosomes, lysosomes, and endolysosomes, as TLR 3, 7, 8, and 9, which recognize microbial nucleic acids. ${ }^{15,16}$

Each TLR recognizes a standard component, such as the TLR4, which recognizes the lipopolysaccharide (LPS), and its signaling induces the secretion of type 1 IFNs and other pro-inflammatory cytokines. ${ }^{11,13,16}$ By contrast, activation through other TLRs, such as the heterodimers of TLR1-TLR2 and TLR2-TLR6 or the homodimer of TLR5, leads to the secretion of pro-inflammatory cytokines, but without the production of IFNs. ${ }^{3}$

The heterodimers TLR1-TLR2 and TLR2-TLR6 recognize bacteria and micoplasmas. TLR3 acts in the prevention of viral infections, by recognizing the double ribbon of RNA (dsRNA). ${ }^{15}$ TLR7 and 8 recognize the double ribbon of viral RNA (ssRNA); TLR9 recognizes the components containing CpG in the DNA, and TLR11 recognizes uropathogenic bacteria (Chart 2). ${ }^{14}$

There are two possible mechanisms of sensitization to contact allergens: one is the dependent IL-12, in which the isolated activation of TLR2 or TLR4 is enough to develop ACD, and an independent IL-12 mechanism, which requires the activation of both TLR2 and TLR4. ${ }^{3,17}$ TLR2 and TLR4 do not directly recognize the hapten, but these are able to recognize endogenous bonds that are present in the skin.,12 The low-wieght molecules, derived from hyaluronic acid (HA), activate the DCs in vitro via TLR2 and TLR4, while the degradated HA acts as an endogenous activator of TLR2 and TLR4, signaling the ACD response. ${ }^{3}$

The nickel ion $(\mathrm{Ni2}+)$ is one of the most common causes of ACD ${ }^{18}$ It directly activates TLR4 in such a way that the transgenic expression of TLR4 in an individual that lacks this results in an effective sensitization, indicating the crucial role of TLR4 in allergies to $\mathrm{Ni2}+{ }^{18,19}$ In addition to $\mathrm{Ni2}+$, cobalt $(\mathrm{Co} 2+)$ and palladium $(\mathrm{Pd})$ ions can also directly activate TLR4, inducing its dimerization and inflam-

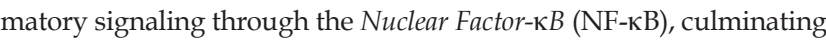
in the production of pro-inflammatory cytokines and chemokines. ${ }^{1,20}$

\section{Inflammassome}

The inflammasome is an intracelular protein complex, formed after the recognition of many inflammatory signals. ${ }^{3}$ The contact allergens activate the innate immune system through a complex mechanism involving TLRs, the NLR3 inflammasome (members of the NOD-Like Receptors (NLRs) family), and signs of endogenous damage, such as the extracellular Adenosine Triphosphate (ATP) and reactive oxygen species (ROS). 2,17,19 The extracellular ATP can act as a danger signal (DAMP) upon bonding to the puriner-

CHART 2: Toll-like receptor and inflammasome bonds

\begin{tabular}{|c|c|c|c|}
\hline Extracellular & Agonist & Allergen & $\begin{array}{l}\text { Synthetic } \\
\text { agonists }\end{array}$ \\
\hline \multicolumn{4}{|l|}{ TLR1 and 2} \\
\hline TLR2 and 6 & $\begin{array}{l}\text { Bacteria - } \\
\text { peptidoglycan, } \\
\text { lipoproteins, } \\
\text { LTA, fungus - } \\
\text { zymosan }\end{array}$ & $\begin{array}{l}\text { Fragments } \\
\text { of HA }\end{array}$ & $\begin{array}{l}\text { Pam3Cys, } \\
\text { diacilated } \\
\text { lipopro- } \\
\text { tein }\end{array}$ \\
\hline TLR4 & Bacteria - LPS & & \\
\hline \multicolumn{4}{|l|}{$\begin{array}{l}\text { Fungus - Ma- } \\
\text { nana Protozoan } \\
\text { - glycoinosi- } \\
\text { tolphospholi- }\end{array}$} \\
\hline pid & $\begin{array}{l}\mathrm{Ni} 2+, \mathrm{Co} 2+, \\
\text { Pd, mites, } \\
\text { DNFB, TNCB, } \\
\text { Fragments of } \\
\text { HA }\end{array}$ & $\begin{array}{l}\text { Monophos- } \\
\text { phoril lipid } \\
\text { A }\end{array}$ & \\
\hline TLR5 & $\begin{array}{l}\text { Bacteria - } \\
\text { flagellin }\end{array}$ & & \\
\hline TLR11 & $\begin{array}{l}\text { Bacteria uropa- } \\
\text { togenic }\end{array}$ & & \\
\hline \multicolumn{4}{|l|}{$\begin{array}{l}\text { Protozoan - } \\
\text { profilin-simile }\end{array}$} \\
\hline \multicolumn{4}{|l|}{ Intracellular } \\
\hline TLR3 & Virus - dsRNA & & Poly I:C \\
\hline TLR7 and TLR8 & Virus - ssRNA & & $\begin{array}{l}\text { Imiqui- } \\
\text { mod }\end{array}$ \\
\hline \multicolumn{4}{|l|}{ R848, CL097 } \\
\hline TLR9 & $\begin{array}{l}\text { Bacteria - CpG } \\
\text { DNA }\end{array}$ & & \\
\hline \multicolumn{4}{|l|}{$\begin{array}{l}\text { Virus - CpG } \\
\text { DNA }\end{array}$} \\
\hline $\begin{array}{l}\text { Protozoan - } \\
\text { CpG DNA }\end{array}$ & & CpG-ODNs & \\
\hline NLR3 & $\begin{array}{l}\text { ATP, > } 30 \\
\text { different stim- } \\
\text { uli, PAMPs, } \\
\text { DAMPs }\end{array}$ & $\begin{array}{l}\text { DNTB, } \\
\text { TNCB, } \\
\text { DNFB }\end{array}$ & $\begin{array}{l}\text { Alum } \\
\text { crystals, } \\
\text { silicone } \\
\text { nano- } \\
\text { particles, } \\
\text { nigericin }\end{array}$ \\
\hline
\end{tabular}

PAMPs: Pathogen-Associated Molecular Patterns; DAMPs: Damage-Associated Molecular Patterns; Ni2+: nickel; Co2+: cobalt; Pd: palladium; HA: hyaluronic acid; LTA lipoteichoic acid; LPS: lipopolysaccharide; dsRNA: double ribbon RNA; ssRNA: single ribbon RNA; CPG-ODNs: oligodeoxinucleotides containing CPG motives, household dust mites; DNTB: dinitrotiocianobenzene; TNCB: trinitrochlorobenzene; DNFB: dinitrofluorobenzene; NLR3: inflammasome; ATP: adenosine triphosphate. 
gic receptor $\mathrm{P} 2 \mathrm{X} 7$, activating the inflammasome and promoting the maturation of IL-1 $\beta .^{21}$ The ATP, the main carrier of energy within the cell, and the P2X7 are essential for the activation of the NLR3 inflammasome by the contact allergen. ${ }^{22}$

The inflammasome leads to the activation of caspase- 1 , which cleaves pro-IL-1 $\beta$ and pro-IL-18, generating the active pro-inflammatory cytokines. ${ }^{11,16}$ The contact sensitizers, such as haptens, when applied to the skin, induce the processing and secretion of IL-1 $\beta$ and IL-18, dependent on inflammasomes, causing the ACD reaction..$^{23}$ Thus, the exposure of the skin to hapten or high doses of $\mathrm{UV}$ radiation activates the intracellular sensors contained in the inflammasome complex of the keratinocytes, leading to the activation of caspase- 1 and the processing and secretion of pro-inflammatory cytokines. Successive exposure results in the activation of immune cells residing in the tissues that induce and perpetuate the inflammatory response. ${ }^{16}$

\section{Innate immune response cells Keratinocytes}

The keratinocytes are essential for the development of ACD, due to their abundance in the epidermis and to their role in the formation of the skin's anatomical barrier function. ${ }^{3}$ Although the haptens can penetrate through the intact skin, the importance of an intact cutaneous barrier can limit the sensitivity to ACD, based on the observation that specific diseases that hinder the barrier function have an increased risk of sensitization through the application of topical medicines. ${ }^{3}$ The keratinocytes express TLRs and answer to hapten, activating the TLR4, such as the dinitrofluorobenzene (DNFB) and Ni2+. ${ }^{3,14}$

The keratinocytes secrete cytokines, such as IL-6, IL-10, IL18 , and TNF, in addition to IL-1 $\beta$ and IL- $18 .{ }^{24}$ Of particular importance is the TNF, which, together with IL-1 $\beta$ and IL-18, is necessary for the maturation and migration of the DC induced by hapten, from the skin to the dLN. ${ }^{3,25}$

\section{Dendritic Cells}

The main function of the DCs is to recognize and process external antigens and migrate to the dLNs, where they present the antigens to naïve T cells. ${ }^{26}$ These are specialized cells and present subtypes, such as Dermal Dendritic Cells (dDCs), Plasmacytoid Dendritic Cells (pDCs), and Langerhans Cells (LCs), which are the only DCs in the epidermis. ${ }^{27}$ DCs remain in an immature state in the skin and, when the haptens penetrate the dermis and are captured by the $\mathrm{dDCs},{ }^{3}$ there is a release of pro-inflammatory cytokines, such as IL-1 $\beta$ and TNF- $\alpha$, favoring the maturation and migration of dDCs to the dLNs, colonizing the paracortex regions. ${ }^{26,28,29}$

After the contact with the antigen in the dermis, the dDCs diminish their migration speed and adopt the morphology characterized by multiple dendrites. Although the LCs and dDCs have the capacity to present antigens, they show different kinetics. ${ }^{30}$ The presentation of the antigen is necessary in the sensitization and elicitation stages, which is important to evaluate the relevance of the subtypes of DCs in each stage. The depletion of DCs in the skin of sensitized mice increases the elicitation stage, which suggests a regulatory function in this stage performed by some subtype of DC. ${ }^{18}$
Among the populations of DCs, that which most produces type 1 IFN is $\mathrm{pDC} .{ }^{16} \mathrm{pDC}$ produce all type 1 IFN subtypes, called IFN- $\alpha$, IFN- $\beta$, IFN-1, IFN-w, and IFN-t. ${ }^{31,32}$ The type 1 IFNs resulting from $\mathrm{pDC}$ activate the production of IL-12, IL-15, IL-18, and IL-23 by Myeloid Dendritic Cells (mDCs) and induce the monocytes to differentiate themselves into DCs. They also stimulate the NK cells and, together with IL-6, they lead the B cells to differentiate themselves into secreting plasmatic cells of antibodies. ${ }^{32-34}$ In addition, the pDCs increase the ability of the mDCs to carry out a cross presentation of exogenous antigens for the T CD8+ cells, promote their clonal explansion, and induce the differentiation of the Th1 cells. ${ }^{35}$

The langerina ${ }^{+} \mathrm{dDC}$ comprise a distinct subtype of DC derived from the precursors of bone marrow and represent a small percentage $(\sim 3 \%)$ of the total population of DCs in the dermis. Being in a dynamic state of flow, they are continually replaced by nine recruited cells. ${ }^{36}$ Another dermal population is the langerina- dDCs, which make up the majority of dDCs $(\sim 80 \%) .{ }^{3,36}$

With the evidence provided by langerina ${ }^{+} \mathrm{dDCs}$, the relevance of the epidermal LCs, such as APCs, have been questions in the cutaneous immune responses. ${ }^{8}$ The LCs were considered to be central cells in the presentation of antigens in the sensitization stage, as they possessed a potent ability to present antigens in vitro and because they were abundant in the epidermis. However, the langerina $^{+}$dDCs, and not the LCs, play an important role in sensitization, as they have sensitizing effects. ${ }^{18,26,37-39}$

\section{Neutrophils}

The neutrophils can exercise an important antimicrobial and pro-inflammatory reaction through the production of ROS and are found in the inflammatory lesions of the skin of patients with ACD. ${ }^{40}$ A neutrophil infiltrate is detected in the skin just a few hours after sensitization and reaches a peak in approximately 24 hours. ${ }^{2}$ One deficiency of neutrophils in the sensitization can lead to a reduction in the induction and migration of DCs to the dLNs and to the deficiency in the induction of specific T cells toward the antigen. ${ }^{2}$ The neutrophils are involved in the stages of sensitization and elicitation of $\mathrm{ACD}$, illustrating that they play a decisive role in the various stages, which was verified in a wide range of inflammatory models of skin allergy. ${ }^{2,41}$

\section{Mast cells}

Mast cells are hematopoietically derived cells that reside for a long period of time in barrier tissues, such as the skin and the intestine. Mast cells express a high affinity to the IgE receptor (FcERI), express TLRs 1-4, 6, 7, and 9, and respond to the various microbial products. ${ }^{42}$ In the reaction mediated by $\mathrm{IgE}$, the immediate release of pre-formed granules containing histamine, proteases, proteoglycans, and TNF. ${ }^{3}$ The mast cells also secrete late pro-inflammatory mediators, such as IL-3, IL-4, IL-5, IL-6, IL-8, IL-9, IL-11, IL-13, TNF, and chemokines, such as CCL2, CCL3, and CCL4. ${ }^{3}$

During the sensitization stage, as they promote their own recruitment, the mast cells are required by the contact allergen, inducing local inflammation, activation, and migration of the DCs, and the generation of allergen-specific T cells. ${ }^{2}$ The contact allergens trigger the mast cells to secrete histamine, which itself acts in the endothelial 
cells and contributes to the recruitment and infiltration of neutrophils during the sensitization stage of ACD. ${ }^{18,43}$ The depletion or absence of mast cells before sensitization hinders the migration/maturation of CD8+ T cells, ${ }^{18,43}$ thus reducing the appearance of ACD..$^{1,41}$

\section{Natural Killer (NK) Cells}

NK cells are of lymphoid origin, but they do not reorganize the T-Cell Receptors (TCR) to recognize antigens. ${ }^{44}$ The NK cells accumulate in many inflammatory skin diseases, such as psoriasis, lichen planus, and ACD. In ACD, the NK cells represent only $10 \%$ of the lymphocyte infiltrate and are triggered by secreted cytokines in the location of contact due to the Th1 and Th17 cell infiltrate. ${ }^{44}$ There are two types of NK human cells, which are defined according to its functional properties, migratory capacity, and expression of the surface markers. ${ }^{45}$ The majority of circulating NK cells are CD56 $6^{\text {low- }}$ $\mathrm{CD}^{+} 6^{+}$, express low levels of perforins, and have a strong cytotoxic capacity. By contrast, NK cells CD56 ${ }^{\text {high }} \mathrm{CD} 16$ - constitute $10-15 \%$ of the circulating NK lymphocytes; however, these are predominantly found in the secondary lymphoid organs, and store low levels of perforins, though they possess immunomodulatory functions and release high levels of cytokines. ${ }^{44,46}$

The subpopulation of NK cells CD56 ${ }^{\text {high }} \mathrm{CD} 166^{-} \mathrm{CD} 62 \mathrm{~L}^{-}$is specifically recruited in the cutaneous inflammations and directly aggravates the reactions of ACD, due to the release of IFN- $\gamma$ and TNF- $\alpha$ and because they induce apoptosis of keratinocytes.$^{41}$ The NK cells lead to a rapid cleavage of the adherence molecules, such as e-cadherins, and the loss of cohesion of keratinocytes and spongiosis. ${ }^{44,47}$

Since the NK cells originate from the lymph nodes, they return to the blood and migrate to the liver, where they remain as hepatic memory cells specific to the antigen, which have a long life and are in constant change with the blood to inspect the peripheral tissues. ${ }^{26,48} \mathrm{~A}$ new provocation of the skin with the same hapten leads to the recruitment and/or conservation of NK memory cells specific to the antigen and can quickly respond to the hapten for at least 3 to 4 months. ${ }^{48}$

\section{$\gamma \delta$ T cells}

$\gamma \delta$ T cells are T cells that express heterodimers of the $\gamma$ and $\delta$ chains of TCR. ${ }^{3}$ These cells are present in tissues, such as the intestine and skin, without originating from lymphoid tissues; express limited or invariable TCRs; and show a phenotype that is similar to that of $\mathrm{T}$ cells, which allows them to react quickly to the provocation of antigens. ${ }^{16}$ In the skin, $\gamma \delta \mathrm{T}$ cells consist of a small proportion of the total $\mathrm{T}$ cells in the dermis (2-9\%) and epidermis (1-10\%). ${ }^{16}$ The localization in the epidermis favors the contact with the hapten during the sensitization stage of $\mathrm{ACD}^{3}$ and are capable of activating dDCs through the production of TNF and IFN- $\gamma .{ }^{16}$

The $\gamma \delta \mathrm{T}$ cells produce growth factors that are essential to healing wounds, such as the connective tissue growth factor, the fibroblast growth factor-9, and the keratinocyte growth factor. ${ }^{16,49}$ In addition, the $\gamma \delta \mathrm{T}$ and NK cells produce cytokines that are generally associated with the Th1, Th2, and Th17 cells. ${ }^{16}$

\section{Innate Lymphoid Cells (ILCs)}

The ILC family includes not only the classic NK cytotoxic cells and the Lymphoid Tissue Inducer Cells (LTi), such as the non-cy- totoxic ILC population. ${ }^{50,51}$ These are characterized by the classic morphology of lymphoid cells, but there is a lack of molecule expressions on the cell surface that identify other immune cell types. ${ }^{50}$ Members of the ILC family indicate that the NK cells and non-cytotoxic ILC helper are independent strains. The non-cytotoxic ILCs consist of three distinct groups: ILCs-1, ILCs-2, and ILCs-3, including LTi. ${ }^{52,53}$ In this sense, the non-cytotoxic ILC cells are capable of producing IFN- $\gamma$ and TNF, and are involved in bacterial and parasitic intracellular immunity. ${ }^{54}$ The ILCs- 2 produce the type 2 cytokines, such as IL-4, IL-5, IL-9, and IL-13, in response to the epitelial cytokines IL-25, IL-33, and Thymic Stromal Lymphopoetin (TSLP), as well as produce the epidermal growth factor receptor and promote the necessary inflammation for anthelmintic immunity, allergic inflammation, and tissue repair. ${ }^{50,55,56}$ Depending on the stimulus, the ILCs3 produce IL-17A, IL-17F, IL-22, TNF, and Granulocyte-Macrophage Colony-Stimulating Factor (GM-CSF) and can promote antibacterial immunity, chronic inflammation, or tissue repair. The ILC-1, ILC-2, and ILC-3 subtypes exhibit a functional similarity to the T-helper cells in terms of the expression of cytokines and the potential effector function (Chart 3). ${ }^{51}$

\section{Initial importance of cytokines}

The keratinocytes actively regulate the magnitude of the

\begin{tabular}{|ll|}
\hline \multicolumn{3}{|c|}{ CHART 3: Non-cytotoxic ILC groups } \\
\hline ILC: & \\
ILC-2: & Production of IFN- $\gamma$ and TNF. \\
- & Pacterial and parasitic intracellular immunity. \\
- & $\begin{array}{l}\text { Anthelmintic immunity, allergic inflammation, and } \\
\text { tissue repair. }\end{array}$ \\
ILC-3: & \\
- & $\begin{array}{l}\text { Production of IL-17A, IL-17F, IL-22, TNF, and GM-CSF } \\
\text { (Granulocyte-Macrophage Colony-Stimulating Factor). }\end{array}$ \\
& $\begin{array}{l}\text { Antibacterial immunity, chronic inflammation, and } \\
\text { tissue repair. }\end{array}$ \\
\hline
\end{tabular}

\begin{tabular}{|c|c|}
\hline & Chart 4: Chemokines \\
\hline \multicolumn{2}{|c|}{ CXCL9, CXCL10, and CXCL11: } \\
\hline$\bullet$ & Chemotactics of Th1 cells. \\
\hline$\bullet$ & Attraction of neutrophils. \\
\hline \multicolumn{2}{|l|}{ CCL2: } \\
\hline • & $\begin{array}{l}\text { Attraction of monocytes, DCs, LCs, memory T cells, } \\
\text { and NK (Natural Killer) cells. }\end{array}$ \\
\hline \multicolumn{2}{|l|}{ CCL20: } \\
\hline - & $\begin{array}{l}\text { Attraction of memory T cells and LCs toward the } \\
\text { skin. }\end{array}$ \\
\hline \multicolumn{2}{|l|}{ CCL27: } \\
\hline - & Expressed by keratinocytes. \\
\hline - & $\begin{array}{l}\text { Attraction of resident cutaneous T lymphocytes } \\
\text { that express CLA (Cutaneous Lymphocyte-Associated } \\
\text { Antigen). }\end{array}$ \\
\hline
\end{tabular}


immune response through the release of chemotactic factors that influence the quality and magnitude of the lymphocyte infiltrate and synthesize chemokines, which are decisive in attracting T CD8+ and CD4+ lymphocytes, thus amplifying the reaction of ACD. ${ }^{44,57}$

In response to pro-inflammatory cytokines, such as IFN- $\gamma$ and TNF- $\alpha$, the keratinocytes produce the CXC chemokines. The CXCL9, CXCL10, and CXCL11 chemokines are chemokines specifically from Th1 cells and selectively attract neutrophils. CCL2 is capable of attracting monocytes, DCs, LCs, memory T cells, and NK cells. ${ }^{16}$ CCL20 attracts memory T cells and LCs in the direction of the skin. ${ }^{58}$ CCL27 is exclusively and constitutively expressed by keratinocytes and preferentially attracts resident cutaneous $\mathrm{T}$ lymphocytes that express the Cutaneous Lymphocyte-Associated Antigen (CLA) (Chart 4). ${ }^{16,59}$

\section{EFFECTOR RESPONSE}

The mechanism of cellular infammatory infiltrate in the effector stage uses the inflammatory signals that are antigen-non-specific and antigen-specific. ${ }^{18}$

Antigen-non-specific inflammation - activation of keratinocytes, neutrophils, and mast cells

The keratinocytes, neutrophils, and mast cells are essential factors to generate the antigen-non-specific inflammation in the elicitation or effector stage. ${ }^{18}$ First, the haptens stimulate the keratinocytes to produce pro-inflammatory cytokines, such as IL-1 $\beta$ and TNF- $\alpha$. These cytokines activate the vascular endothelial cells to express adhesion molecules, such as ICAM-1 and P/E selectin, which guides the T cells in the blood to transmigrate to the tissues. ${ }^{23}$
The haptens also increase vascular permeability through histamine resulting from mast cells and trigger the keratinocytes to produce chemokines that aid the neutrophils to infiltrate into the skin, favoring the infiltration of the T CD8+ cells. ${ }^{41,43}$

When the concentration of the haptens is not raised enough to provoke the antigen-non-specific inflammation, the $\mathrm{ACD}$ reaction does not occur. ${ }^{18}$

\section{Antigen-specific inflammation - T-cell activation}

Following the antigen-non-specific inflammation, the antigen-specific inflammation begins, mediated by T cells. ${ }^{18}$ When these infiltrate in the skin, they are activated by cutaneous APCs and produce IFN- $\gamma$ and IL-17, which stimulate cells that reside in the skin, leading to the additional recruitment of $\mathrm{T}$ cells and intensifying inflammation..$^{60}$ Each subtype of T cells (helper - Th and cytotoxic $\mathrm{Tc}$ ) trigger the cells in the skin differently and create their specific type of inflammation (Figure 2). ${ }^{18,61}$

\section{CHART 5: Th1/Tc1, Th2/Tc2, and Th17/Tc17 cells and their main} cytokines

Th1/Tc1:

Secrete IFN- $\gamma$ and IL-2.

Th2/Tc2:

Secrete IL-4, IL-5, and IL-13.

\section{Th17/Tc17:}

Secrete IL-6, IL-17A, IL-17F, IL-21, IL-22, IL-26, TNF- $\alpha$, and GMCSF (Granulocyte-Macrophage Colony-Stimulating Factor).

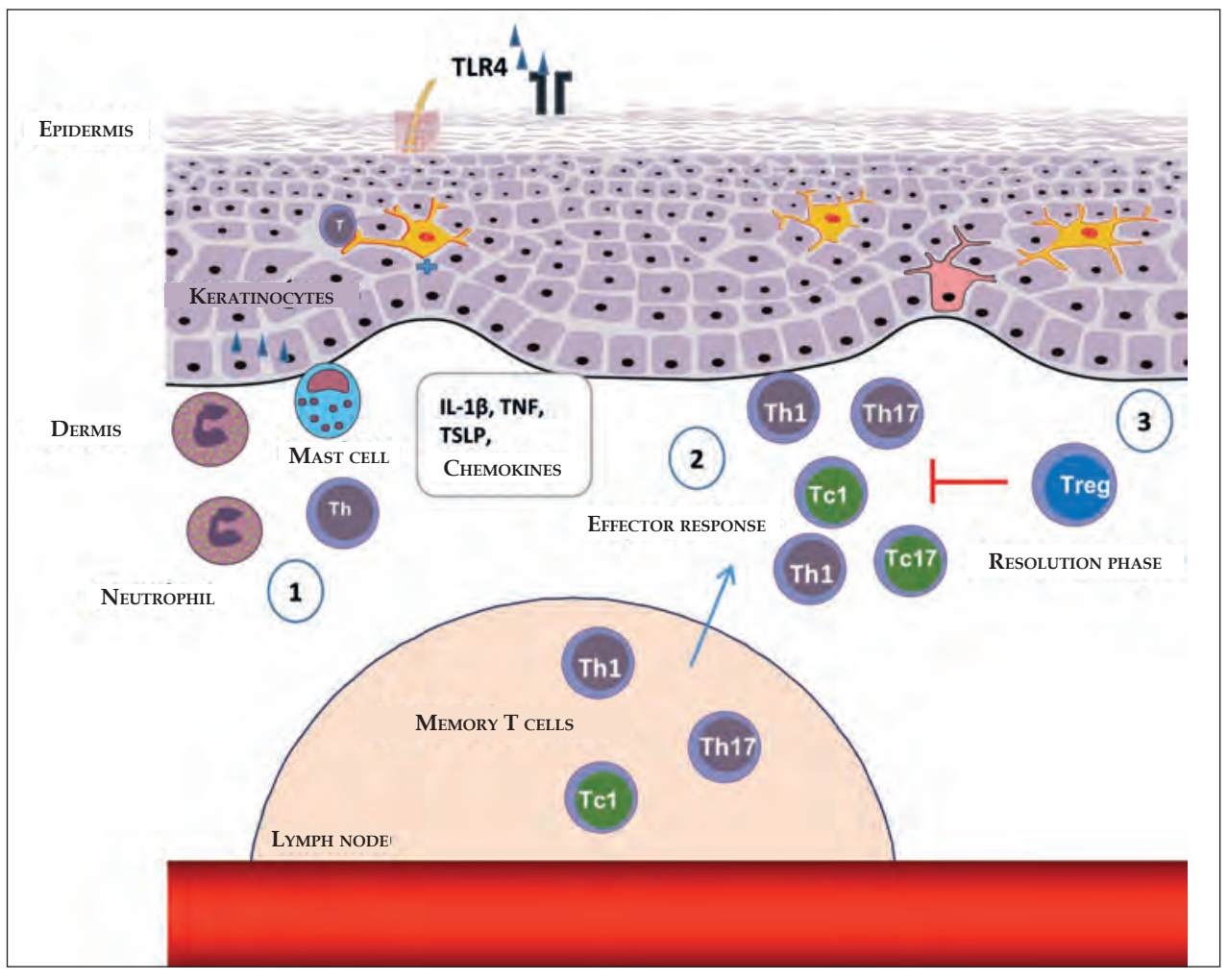

Figure 2: Steps in the stages of elicitation and resolution of the contact dermatitis. (1) After reexposure to the haptens, antigen-specific $\mathrm{T}$-cell infiltration occurs, favored by the production of chemokines and cytokines through keratinocytes, mast cells, and neutrophils. (2) The Th1, Th17, ou T CD8+ antigen-specific $\mathrm{T}$ cells, which secrete IFN- $\gamma$ (Tc1) or IL-17 (Tc17), produce cytokines that induce the infiltration of additional inflammatory cells. (3) In the resolution stages, the Tregs infiltrate in the inflammatory sites and perform a suppressor function, contributing to the finalization of the inflammatory response 


\section{T CD4+ and T CD8+ effector cells}

$\mathrm{T}$ CD8+ cells have pro-inflammatory effector functions, while the T CD4+ cells have pro-inflammatory and anti-inflammatory functions, which are dependent on the production of their cytokines or their subtypes. ${ }^{18}$

The effector cell is predominantly the T CD8+ lymphocyte, and the deletion of the Tc1 CD8+ cells has a greater suppressor effect than the deletion of Th1 CD4+ cells. Thus, the Th1 CD4+ and Tc1 CD8+ cells are effectors in ACD. ${ }^{62}$

The expansion of Ni2+-specific Tc1 CD8+ cells is decisive for the development of the contact allergy to Ni2+. ${ }^{6}$ However, the intensity of the inflammatory reaction is controlled mainly by the CD4+ effector T cells, which are predominant in the skin with ACD and release pro-inflammatory cytokines, in turn affecting the immune function of the resident cells. ${ }^{63}$

\section{The role of Th1/Tc1, Th2/Tc2, and Th17/Tc17 cells}

The T CD4+ and T CD8+ cells can be divided into at least three relevant subtypes for the cutaneous imune response: Th1/Tc1, Th2/Tc2, and Th17/Tc17 cells. The Th1/Tc1 cells are characterized by the secretion of IFN- $\gamma$ and IL-2; the Th2/Tc2 cells secrete IL-4, IL5, and IL-13 ${ }^{18,64}$; and the Th17/Tc17 cells cause the secretion of IL-6, TNF-a, GM-CSF, IL-17A, IL-17F, IL-21, IL-22, and IL-26 (Chart 5). ${ }^{64,65}$

The IFN- $\gamma$ acts in the keratinocytes to produce Th1 cytokines, leading to the infiltration of inflammatory cells in the skin during the effector stage. ${ }^{18,66}$ IFN- $\gamma$ and the cytokines produced by the T CD8+ (Tc1) and Th1 CD4+ cells promote ACD, while the type 2 cytokines, derived from $\mathrm{Th} 2 / \mathrm{Tc} 2$ cells, negatively regulate them. ${ }^{18,62,66}$

The ACD caused by Ni2+ induces the Th17 cells, which are capable of stimulating pro-inflammatory cytokines, chemokines, and adhesion molecules produced by keratinocytes. ${ }^{67}$ IL-17 plays a stimulatory role in the sensitization and effector stages, and the IL-17 (Tc17) secretion cells are detected in the infiltrations of acute lesions and in all types of eczemas. ${ }^{7}$ The Ni2+-specific T CD4+ cells can secrete IL-17, and this shapes many pro-inflammatory functions of the keratinocytes, as well as acts in the recruitment of eosinophils for the eczematous cutaneous lesions., 65,67

\section{Resident $\mathrm{T}$ cells in the skin, such as immune sentinels}

The $\mathrm{T}$ cells that reside in the skin play an important role in immunological homeostasis and memory response. ${ }^{68}$ Memory $\mathrm{T}$ cells in the skin are strategically positioned as the first line of defense against the secondary provocation of the antigen and are important effector cells in the skin. Moreover, much like the T CD4+ cells, these are triggered by the skin's DCs, resulting in the local proliferation of the antigen-specific CD8+ memory T cells. ${ }^{16,69}$

The pro-inflammatory cytokines and chemokines resulting from the T cells can promote a stimulus for the epithelial and mesenchymal cells, including keratinocytes and fibroblastos, thus amplifying the inflammatory reaction. In addition, the T cells in the skin can migrate to the epidermis and cross-attack an epithelial cell. ${ }^{16}$

\section{REGULATOR RESPONSE}

Regulator $T$ cells

The Treg cells consist of a heterogeneous subfamily of $\mathrm{T}$ lymphocytes, which suppress the immune response through the release of anti-inflammatory cytokines or by deactivating the effector T cells through cell-cell contact, through the Cytotoxic T-Lymphocyte Antigen 4 (CTLA-4). ${ }^{26}$ These exist in all lymphoid tissues and include approximately $10 \%$ of all $\mathrm{T}$ cells in the normal skin, with a high proportion remaining in a resting state, especially in pilous follicles. ${ }^{70}$ Few can be found in the interfollicular dermis; the majority are located near the follicular epithelium. ${ }^{71}$

Tregs can be classified according to their origin: Natural Treo Cells (nTreg) of thymic origin and the Peripheral Treg Cells (pTreg). Both respond to antigenic recognition through their expansion, increase in suppressive capacity, and accumulation in the tissue where the antigen is located. ${ }^{72}$ They can suppress the activation, proliferation, and effector functions of a wide range of cells, such as CD4+, $\mathrm{CD} 8+, \mathrm{NK}$, and APCs. ${ }^{73}$

Tregs exercise their regulatory function through the secretion of suppressor cytokines, especially IL-10, as well as by dependent factors of cell-cell contact, such as CD39/CD73 and granzyme/ perforin..$^{74,75}$ These act as suppressors of the activation of leucocytes, blocking their influz to the skin through the negative regulation of the selectin E/P expression in the endothelial blood cells. ${ }^{70,76}$ In addition to the direct suppressor action, Tregs indirectly suppress the proliferation of $\mathrm{T}$ cells by affecting the function of the APCs. These also negatively regulate the mast cells through the suppression of their degranulation and anaphylactic response. . $0,77,78^{-10}$

$\mathrm{CD} 4^{+} \mathrm{CD} 25^{+} \mathrm{Foxp}^{+}$Tregs are essential to the maintenance of self-tolerance perfomed by their regulator role, exercising the first line of control, while their depletion leads to an increase in T CD8+ cells, amplifying the ACD. 4,70,79 Forkhead box $p 3$ (Foxp3) gene was identified as a transcriptional factor of the Tregs, and the memory cutaneous Tregs (mTregs) expressed high levels of Foxp3, when compared to mTregs in the peripheral blood..$^{72,80,81}$ In addition to Treg Foxp3 $3^{+}$, there are also other types of Tregs, such as T-regulator Tr1 cells and Th3 lymphocytes, which are induced in the periphery. It is possible that the Treg cells work in a system of cooperation. ${ }^{70}$

The Tr1 cells produce a large quantity of IL-10 and a moderate quantity of IL- 5 and TGF-b, as well as restrict the differentiation and production of IL-12 through DCs, inhibiting the formation of effector and memory cells. These effects are mediated by the IL-10 and result in the suppression of the hapten-specific T CD4+ and CD8+ effector cells. ${ }^{26}$ The Th3 cells produce the antigen-specific TGF-b, exercising the suppressor effect. ${ }^{70}$

The peripheral T CD4+ lymphocytes of the individuals who are not allergic to nickel express a greater quantity of IL-10 and a lower quantity of IFN- $\gamma$ than do allergic patients, that is, non-allergic individuals present a greater quantity of hapten-specific Tr1 cells in the blood and can also be found in the contact sensitivity skin lesions, in which the completion of the process is shaped. ${ }^{26}$

In the resting condition, a significant fraction $(\sim 20 \%)$ of $\mathrm{T}$ CD4+ cells derived from the skin in dLNs are Tregs. ${ }^{77}$ When the skin inflammation is induced after the application of hapten, one can observe a large number of Tregs derived from the skin in dLNs, with a strong capacity to inhibit the proliferation of hapten-specific T cells. ${ }^{82}$ These migrate more selectively in inflammatory conditions (effector stage) than in the stabilization/resting conditions ${ }^{18,83}$ and 
contain suppressor activities that are more potent than the Tregs found in dLNs. ${ }^{18,30,70,83}$ DCs, which express the antigen to the naïve T CD4+ cells form a stable cell-cell contact in the dLNs, and the Tregs interrupt this contact, mainly through their interaction with DCs. ${ }^{30}$

The Tregs capable of circulating toward the dLNs have a potential to remigrate to the skin, supporting the hypothesis that the skin can represent a lymphoid organ, in which the memory T-cell activities are modulated by the Tregs. ${ }^{18,30,83}$

The number of Tregs in the skin significantly increases during the cutaneous inflammatory process, suggesting that they contain a suppressive action in the inflamed location. ${ }^{18}$ Therefore, the cutaneous Tregs play an important role in terminating the ACD reaction and in the control of systemic immune responses. ${ }^{70}$

\section{CONCLUSION}

The development of ACD is unleashed by the cooperation of multiple factors, such as the environment in which the antigen appears, the type of antigen, and the genetic antecedentes. The cutaneous innate immunity acts in the activation of the adaptive im- mune response. Some contact allergens are detected by TLRs and NLR3 inflammasomes, acting in the induction and perpetuation of the inflammatory response. Many types of cells are involved in the innate immunity, such as: keratinocytes, DCs, neutrophils, mast cells, NK cells, gס T, and ILCs, thus contributing to a sequence of immune response events, allowing for the early detection of contact allergens and the development of the local cutaneous inflammatory process. With the expansion of the effector T cells, there is the release of decisive pro-inflammatory cytokines for the development of the contact allergy. The Treg cells also play an essential role in maintaining tolerance and in the control of the inflammatory response. The number o Tregs in the skin increases during the cutaneous inflammatory process, suggesting that the Tregs play a suppressive role in the inflammed location, controlling the ACD reaction.

The initial immunological events of the development of ACD influence the maintenance or regulation of the contact reponse. Understanding how the contact allergens promote ACD is important not only to better understand the skin's inflammatory process, but also in the prevention, diagnosis, and treatment strategies. $\square$

\section{REFERENCES}

1. Martin SF. New concept in cutaneous allergy. Contact Dermatitis. 2015;72:2-10.

2. Weber FC, Németh T, Csepregi JZ, Dudeck A, Roers A, Ozsvári B, et al. Neutrophils are required for both the sensitization and elicitation phase of contact hypersensitivity. J Exp Med. 2015;212:15-22.

3. Kaplan DH, Igyártó BZ, Gaspari AA. Early immune events in the induction of allergic contact dermatitis. Nat Rev Immunol. 2012 Jan 13;12(2):114-24.

4. Vocanson M, Hennino A, Rozières A, Poyet G, Nicolas JF. Effector and regulatory mechanisms in allergic contact dermatitis. Allergy. 2009;64:1699-714.

5. Larsen JM, Bonefeld CM, Poulsen SS, Geisler C, Skov L. IL23 and Th17-mediated inflammation in human allergic contact dermatitis. J Allergy Clin Immunol. 2009;123:486-92.

6. Pennino D, Eyerich K, Scarponi C, Carbone T, Eyerich S, Nasorri F, et al. IL17 amplifies human contact hypersensitivity by licensing hapten nonspecific Th1 cells to kill autologous keratinocytes. J Immunol. 2010;184:4880-8.

7. Simon D, Aeberhard C, Erdemoglu Y, Simon HU. Th17 cells and tissues remodeling in atopic and contact dermatitis. Allergy. 2014;69:125-31.

8. Sampaio SAP, Rivitti EA. Erupções eczematosas. In: Sampaio SAP, Rivitti EA editors. Dermatologia. 3 ed. São Paulo: Artes Médicas; 2007. p.189-208.

9. Kawamura T, Ogawa Y, Aoki R, Shimada S. Innate and intrinsic antiviral immunity in skin. J Dermatol Sci. 2014;75:159-66.

10. Medzhitov R, Janeway CA Jr. Innate immunity: impact on the adaptive immune response. Curr Opin Immunol. 1997;9:4-9.

11. Martinon F, Mayor A, Tschopp J. The inflamasomes: guardians of the body. Annu Rev Immunol. 2009;27:229-65.

12. Martin SF, Esser PR, Weber FC, Jakob T, Freudenberg MA, Schmidt M, et al. Mechanisms of chemical-induced innate immunity in allergic contact dermatitis. Allergy. 2011;66:1152-63.

13. Kawai $\mathrm{T}$, Akira $\mathrm{S}$. The role of pattern-recognition receptors in innate immunity: update on Toll-like receptors. Nat Immunol. 2010;11:373-84.

14. Nestle FO, Di Meglio P, Qin JZ, Nickoloff BJ. Skin immune sentinels in health and disease. Nat Rev Immunol. 2009;9:679-91.

15. Brodsky I, Medzhitov R. Two modes of ligand recognition by TLRs. Cell. 2007;130:979-81.

16. Lebre MC, van der Aar AM, van Baarsen L, van Capel TM, Schuitemaker JH, Kapsenberg ML, et al. Human keratinocytes express functional Toll-like receptor 3, 4, 5, and 9. J Invest Dermatol. 2007:127:331-41.

17. Martin SF, Dudda JC, Bachtanian E, Lembo A, Liller S, Dürr C, et al. Toll-like receptor and IL 12 signaling control susceptibility to contact hypersensitivity. J Exp Med. 2005;205:2151-62
18. Honda T, Egawa G, Grabbe S, Kabashima K. Update of immune events in the murine contact hypersensitivity models: toward the understanding of allergic contact dermatitis. J Invest Dermatol. 2013;133:303-15.

19. Schmidt M, Raghavan B, Müller V, Vogl T, Fejer G, Tchaptchet S, et al. Crucial role for human Toll-like receptor 4 in the development of contact allergy to nickel. Nat Immunol. 2010;11:814-9.

20. Sato N, Kinbara M, Kuroishi T, Kimura $K$, Iwakura $Y$, Ohtsu $H$, et al. Lipopolysaccharide promotes and augments metal allergies in mice, dependent on innate immunity and histidine decarboxylase. Clin Exp Allergy. 2007;37:743-51.

21. Paiva-Oliveira EL, Silva AC, Silva RM, Sevenini LA, Melo HA, Lagrota-Candido $\mathrm{JM}$, et al. Inflamassoma e sua repercussão clínica: revisão da literatura. R Ci Med Biol. 2012;11:96-102.

22. Surprenant A, North RA. Signaling at purinergic P2X7 receptors. Annu Rev Physiol. 2009;71:333-59.

23. Watanabe H, Gaide 0 , Pétrilli V, Martinon F, ContassotE, Roques S, et al. Activation of the IL-1 $\beta$-processing inflammasome is involved in contact hypersensitivity. J Invest Dermatol. 2007;127:1956-63.

24. Corsini E, Galli CL. Epidermal cytokines in experimental contact dermatitis. Toxicology. 2000;142:203-11.

25. Nishibu A, Ward BR, Boes M, Takashima A. Roles for IL-1 and TNF $\square$ in dynamic behavioral responses of Langerhans cells to topical hapten application. J Dermatol Sci. 2007;45:23-30.

26. Martins LEAM, Reis VMS. Immunopathology of allergic contact dermatitis. An Bras Dermatol. 2011;86:410-33.

27. Romani N, Clausen BE, Stoitzner P. Langerhans cells and more: langerinexpressing dendritic cell subsets in the skin. Immunol Rev. 2010;234:120-41.

28. Randolph GJ. Dendritic cell migration to lymph nodes: cytokines, chemokines, and lipid mediators. Semin Immunol. 2001;13:267-74.

29. Kissenpfennig A, Henri S, Dubois B, Laplace-Builhé C, Perrin P, Romani N, et al. Dynamics and function of Langerhans cells in vivo: dermal dendritic cells colonize lymph node areas distinct from slower migrating Langerhans cells. Immunity. 2005;22:643-54

30. Egawa G, Kabashima K.. Skin as a peripheral lymphoid organ: revisiting the concept of skin-associated lymphoid tissues. J Invest Dermatol. 2011;131:2178-85.

31. Ito T, Kanzler H, Duramad O, Cao W, Liu YJ. Specialization, kinetics, and repertoire of type 1 interferon responses by human plasmacytoid predendritic cells. Blood. 2006;107:2423-31.

32. Gilliet M, Cao W, Liu YJ. Plasmocytoid dendritic cells: sensing nucleic acids in viral infection and autoimmune diseases. Nat Rev Immunol. 2008;8:594-606

33. Santini SM, Lapenta C, Logozzi M, Parlato S, Spada M, Di Pucchio T, et al. Type I 
interferon as a powerful adjuvant for monocyte-derived dendritic cell development and activity in vitro and in Hu PBL SCID mice. J Exp Med. 2000;191:1777-88.

34. Jego G, Palucka AK, Blanck JP, Chalouni C, Pascual V, Banchereau J. Plasmacytoid dendritic cells induce plasma cell differentiation through type I interferon and interleukin 6. Immunity. 2003;19:225-34.

35. Kolumam GA, Thomas S, Thompson LJ, Sprent J, Murali-Krishna K. Type I interferons act directly on CD8 T cells to allow clonal expansion and memory formation in response to viral infection. J Exp Med. 2005;202:637-50.

36. Ginhoux F, Collin MP, Bogunovic M, Abel M, Leboeuf M, Helft J, et al. Bloodderived dermal langerin + dendritic cells survey the skin in the steady state. J Exp Med. 2007;204:3133-46.

37. Fukunaga A, Khaskhely NM, Sreevidya CS, Byrne SN, Ullrich SE. Dermal dendritic cells, and not Langerhans cells, play an essential role in inducing an immune response. J Immunol. 2008;180:3057-64.

38. Bursch LS, Wang L, Igyarto B, Kissenpfennig A, Malissen B, Kaplan DH, et al. Identification of a novel population of Langerin + dendritic cells. J Exp Med. 2007;204:3147-56.

39. Honda T, Nakajima S, Egawa G, Ogasawara K, Malissen B, Miyachi Y, et al. Compensatory role of Langerhans cells and langerin-positive dermal dendritic cells in the sensitization phase of murine contact hypersensitivity. J Allergy Clin Immunol. 2010;125:1154-1156.e2.

40. Mantovani A, Cassatella MA, Costantini C, Jaillon S. Neutrophils in the activation and regulation of innate and adaptive immunity. Nat Rev Immunol. 2011;11:519-31.

41. Engeman T, Gorbachev AV, Kish DD, Fairchild RL. The intensity of neutrophil infiltration controls the number of antigen-primed CD8 $T$ cells recruited into cutaneous antigen challenge sites. J Leukoc Biol. 2004;76:941-9.

42. Marshall JS, King CA, McCurdy JD. Mast cell cytokine and chemokine responses to bacterial and viral infection. Curr Pharm Des. 2003;9:11-24.

43. Dudeck A, Dudeck J, Scholten J, Petzold A, Surianarayanan S, Köhler A, et al. Mast cells are key promoters of contact allergy that mediate the adjuvant effects of haptens. Immunity. 2011;34:973-84.

44. Carbone T, Nasorri F, Pennino D, Eyerich K, Foerster S, Cifaldi L, et al. CD56high $\mathrm{CD}^{-} 6^{-} \mathrm{CD}^{-} \mathrm{L}^{-}$NK cells accumulate in allergic contact dermatitis and contribute to the expression of allergic responses. J Immunol. 2010;184:1102-10.

45. Di Santo JP. Functionally distinct NK-cell subsets: developmental origins and biological implications. Eur J Immunol. 2008;38:2948-51.

46. Moretta A, Marcenaro E, Parolini S, Ferlazzo G, Moretta L. NK cells at the interface between innate and adaptive immunity. Cell Death Differ. 2008;15:226-33.

47. Traidl C, Sebastiani S, Albanesi C, Merk HF, Puddu P, Girolomoni G, et al. Disparate cytotoxic activity of nickel-specific CD8+ and CD4+ T cell subsets against keratinocytes. J Immunol. 2000;165:3058-64.

48. Paust S, von Andrian UH. Natural killer cell memory. Nat Immunol. 2011;12:500-8.

49. Toulon A, Breton L, Taylor KR, Tenenhaus M, Bhavsar D, Lanigan C, et al. A role for human skin-resident T cells in wound healing. J Exp Med. 2009;206:743-50.

50. Neill DR, Wong SH, Bellosi A, Flynn RJ, Daly M, Langford TK, et al. Nuocytes represent a new innate effector leukocyte that mediates type-2 immunity. Nature. 2010;464:1367-70

51. Artis D, Spits H. The biology of innate lymphoid cells. Nature. 2015;517:293-301.

52. Spits H, Artis D, Colonna M, Diefenbach A, Di Santo JP, Eberl G, et al. Innate lymphoid cells - a proposal for uniform nomenclature. Nat Rev Immunol. 2013;13:145-9.

53. Constantinides MG, McDonald BD, Verhoef PA, Bendelac A. A committed precursor to innate lymphoid cells. Nature. 2014;508:397-401.

54. Klose CS, Flach M, Möhle L, Rogell L, Hoyler T, Ebert K, et al. Differentiation of type 1 ILCs from a common progenitor to all helper-like innate lymphoid cell lineages. Cell. 2014:157:340-56.

55. Salimi M, Ogg G. Innate lymphoid cells and the skin. BMC Dermatol. 2014;14:18.

56. Kim BS, Siracusa MC, Saenz SA, Noti M, Monticelli LA, Sonnenberg GF, et al. TSLP elicits IL-33-independent innate lymphoid cell responses to promote skin inflammation. Sci Transl Med. 2013;5:170ra16.

57. Sebastiani S, Albanesi C, De PO, Puddu P, Cavani A, Girolomoni G. The role of chemokines in allergic contact dermatitis. Arch Dermatol Res. 2002;293:552-9.

58. Charbonnier AS, Kohrgruber N, Kriehuber E, Stingl G, Rot A, Maurer D. Macrophage inflammatory protein $3 \alpha$ is involved in the constitutive trafficking of epidermal Langerhans cells. J Exp Med. 1999;190:1755-68.

59. Homey B, Alenius H, Müller A, Soto H, Bowman EP, Yuan W, et al. CCL27-CCR10 interactions regulate T cell-mediated skin inflammation. Nat Med. 2002;8:157-65.

60. Mitsui G, Mitsui K, Hirano T, Ohara 0, Kato M, Niwano Y. Kinetic profiles of sequential gene expressions for chemokines in mice with contact hypersensitivity. Immunol Lett. 2003;86:191-7.
61. He D, Wu L, Kim HK, Li H, Elmets CA, Xu H. IL-17 and IFN-gamma mediate the elicitation of contact hypersensitivity responses by different mechanisms and both are required for optimal responses. J Immunol. 2009;183:1463-70.

62. Ishizaki K, Yamada A, Yoh K, Nakano T, Shimohata H, Maeda A, et ak. Th1 and type 1 cytotoxic $T$ cells dominate responses in T-bet over expression transgenic mice that develop contact dermatitis. J Immunol. 2007;178:605-12.

63. Albanesi C, Scarponi C, Giustizieri ML, Girolomoni G. Keratinocytes in inflammatory skin diseases. Curr Drug Targets Inflamm Allergy. 2005;4:329-34.

64. Weaver CT, Hatton RD, Mangan PR, Harrington LE. IL-17 family cytokines and the expanding diversity of effector T cell lineages. Annu Rev Immunol. 2007;25:821-52.

65. Ricciardi L, Minciullo PL, Saitta S, Trombetta D, Saija A, Gangemi S. Increased serum levels of IL22 in patients with nickel contact dermatitis. Contact Dermatitis. 2009:60:57-8.

66. Mori T, Kabashima K, Yoshiki R, Sugita K, Shiraishi N, Onoue A, et al. Cutaneous hypersensitivities to hapten are controlled by IFN- $\gamma$-upregulated keratinocyte Th1 chemokines and IFN- $\gamma$-downregulated langerhans cell Th2 chemokines. J Invest Dermatol. 2008;128:1719-27.

67. Albanesi C, Scarponi C, Cavani A, Federici M, Nasorri F, Girolomoni G. Interleukin-17 is produced by both Th1 and Th2 lymphocytes, and modulates interferon-gamma- and interleukin-4-induced activation of human keratinocytes. J Invest Dermatol. 2000;115:81-7.

68. Boyman 0, Conrad C, Tonel G, Gilliet M, Nestle FO. The pathogenic role of tissueresident immune cells in psoriasis. Trends Immunol. 2007;28:51-7.

69. Wakim LM, Waithman J, van Rooijen N, Heath WR, Carbone FR. Dendritic cell-induced memory $\mathrm{T}$ cell activation in nonlymphoid tissues. Science. 2008;319:198-202.

70. Honda T, Miyachi Y, Kabashima K.. Regulatory T cells in cutaneous immune responses. J Dermatol Sci. 2011;63:75-82.

71. Chow Z, Mueller SN, Deane JA, Hickey MJ. Dermal regulatory T cells display distinct migratory behavior that is modulated during adaptive and innate inflammation. J Immunol. 2013;191:3049-56.

72. Gratz IK, Rosenblum MD, Abbas AK. The life of regulatory T cells. Ann N Y Acad Sci. 2013;1283:8-12

73. Sakaguchi S, Ono M, Setoguchi R, Yagi H, Hori S, Fehervari Z, et al. Foxp3+ $\mathrm{CD} 25+\mathrm{CD} 4+$ natural regulatory $\mathrm{T}$ cells in dominant self-tolerance and autoimmune disease. Immunol Rev. 2006;212:8-27.

74. Deaglio S, Dwyer KM, Gao W, Friedman D, Usheva A, Erat A, et al. Adenosine generation catalyzed by $\operatorname{CD} 39$ and $\mathrm{CD} 73$ expressed on regulatory T cells mediates immune suppression. J Exp Med. 2007;204:1257-65.

75. Gondek DC, Lu LF, Quezada SA, Sakaguchi S, Noelle RJ. Cutting edge: contactmediated suppression by $\mathrm{CD} 4+\mathrm{CD} 25$ + regulatory cells involves a granzyme B-dependent, perforin-independent mechanism. J Immunol. 2005;174:1783-6.

76. Ring S, Oliver SJ, Cronstein BN, Enk AH, Mahnke K. CD4+CD25+ regulatory $T$ cells suppress contact hypersensitivity reactions through a CD39, adenosinedependent mechanism. J Allergy Clin Immunol. 2009;123:1287-96.e2.

77. Tadokoro CE, Shakhar G, Shen S, Ding Y, Lino AC, Maraver A, et al. Regulatory T cells inhibit stable contacts between $\mathrm{CD} 4+\mathrm{T}$ cells and dendritic cells in vivo. $J$ Exp Med. 2006;203:505-11.

78. Gri G, Piconese S, Frossi B, Manfroi V, Merluzzi S, Tripodo C, et al. CD4+CD25+ regulatory $T$ cells suppress mast cell degranulation and allergic responses through OX40-0X40L interaction. Immunity. 2008;29:771-81.

79. Sakaguchi S, Miyara M, Costantino CM, Hafler DA. FOXP3 + regulatory T cells in the human immune system. Nat Rev Immunol. 2010;10:490-500.

80. Gratz IK, Truong HA, Yang SH, Maurano MM, Lee K, Abbas AK, et al. Cutting edge: memory regulatory T cells require IL-7 and not IL-2 for their maintenance in peripheral tissues. J Immunol. 2013:190:4483-7

81. Sanchez Rodriguez R, Pauli ML, Neuhaus IM, Yu SS, Arron ST, Harris HW, et al. Memory regulatory T cells reside in human skin. J Clin Invest. 2014;124:1027-36.

82. Tomura M, Honda T, Tanizaki H, Otsuka A, Egawa G, Tokura Y, et al. Activated regulatory $T$ cells are the major $T$ cell type emigrating from the skin during a cutaneous immune response in mice. J Clin Invest. 2010;120:883-93.

83. Kabashima K, Sakata D, Nagamachi M, Miyachi Y, Inaba K, Narumiya S. Prostaglandin E2-EP4 signaling initiates skin immune responses by promoting migration and maturation of Langerhans cells. Nat Med. 2003;9:744-9.

How to cite this article: Silvestre MC, Sato MN, Reis VMS. Innate immunity and effector and regulatory mechanisms involved in allergic contact dermatitis. An Bras Dermatol. 2018;93(2):242-50. 